Bulletin d'Histoire Contemporaine de

l'Espagne

$51 \mid 2017$

Les forces politiques durant la Seconde République espagnole

\title{
Un sueño americano. El Gobierno vasco en el exilio y los Estados Unidos (1937-1979)
}

David Mota Zurdo

\section{(2) OpenEdition Journals}

Edición electrónica

URL: http://journals.openedition.org/bhce/785

DOI: $10.4000 /$ bhce. 785

ISSN: 1968-3723

\section{Editor}

Presses Universitaires de Provence

\section{Edición impresa}

Fecha de publicación: 1 junio 2017

Paginación: 296-301

ISSN: 0987-4135

\section{Referencia electrónica}

David Mota Zurdo, « Un sueño americano. El Gobierno vasco en el exilio y los Estados Unidos (1937-1979) », Bulletin d'Histoire Contemporaine de l'Espagne [En línea], 51 | 2017, Publicado el 09 octubre 2018, consultado el 24 septiembre 2020. URL : http://journals.openedition.org/bhce/785 ; DOI : https://doi.org/10.4000/bhce.785 
Un sueño americano. El Gobierno vasco en el exilio y los Estados Unidos $(1937-1979)^{1}$

\section{David MOTA ZURDO}

La presente tesis doctoral analiza la acción exterior del Gobierno vasco en Estados Unidos entre 1937 y 1979. Esa acción vino definida por una estrategia atlantista orientada a la búsqueda de una relación privilegiada con el Gobierno de Estados Unidos como vía idónea para la recuperación del autogobierno vasco, previa restauración de la legalidad democrática en España. La tesis reconstruye y analiza el proceso de diseño de esta estrategia, sus diferentes fases cronológicas y su evolución, atendiendo a los diversos agentes e instrumentos de la acción exterior del Gobierno vasco. Todo ello en el marco de las relaciones bilaterales entre los Estados Unidos y la España franquista $y$ en el variable contexto internacional determinado por la II Guerra mundial y la Guerra Fría. Asimismo, se analiza la mencionada estrategia atlantista tomando en consideración no sólo las instituciones que representaron esta relación tan singular -y asimétrica-, sino también las personas que la hicieron posible.

Para ello, se han establecido dos planos de análisis: el plano oficial, de las relaciones políticas institucionales con el Departamento de Estado y otras agencias estadounidenses; y el plano de las relaciones personales extraoficiales, mantenidas con figuras

1 Tesis doctoral internacional defendida el 29 de abril de 2015 en el Departamento de Historia Contemporánea de la Universidad del Pais Vasco-Euskal Herriko Unibertsitatea (UPVEHU). Directores: Coro Rubio Pobes y Santiago de Pablo Contreras (UPV-EHU). Presidente: Ludger Mees (UPV-EHU). Secretario: Óscar Álvarez Gila (UPV-EHU). Vocales: Xabier Irujo (Univ. de Nevada, Reno), Leyre Arrieta (Univ. de Deusto) y Ricardo Martin de la Guardia (Univ. de Valladolid). influyentes de la vida política y social estadounidense en una actividad de lobbying.

Durante una fase inicial, correspondiente a los años de la Guerra Civil española (1936-1939), las actividades del Gobierno vasco en los Estados Unidos se limitaron al establecimiento de la delegación en Nueva York, la propaganda antifranquista, la búsqueda de financiación y las iniciativas para promover el levantamiento del embargo de armas a la España republicana. Desde el primer momento, los delegados vascos buscaron acercarse a la opinión pública católica estadounidense para ganarse su simpatía, creyendo que con su apoyo tendrían un acceso más directo a la Casa Blanca y que, gracias a su colaboración y presión, podrían convencer al Gobierno de Franklin D. Roosevelt de que revocara su apoyo a la política de No Intervención en la Guerra Civil española.

A tal efecto, mostraron al medio católico estadounidense su interpretación sobre la Guerra Civil y sobre la cuestión vasca. De igual modo, emprendieron estemismotipode gestiones ante miembros del Departamento de Estado, congresistas y sindicalistas. Sin embargo, al mantenimiento de la política de No Intervención por parte del Gobierno de los Estados Unidos - política que fue motivada por las presiones de influyentes funcionarios del Departamento de Estado, cuyo objetivo era la salvaguarda de los intereses estadounidenses en España-siguió el relativamente rápido reconocimiento del Gobierno franquista el 1 de abril de 1939 , coincidiendo con el final de la Guerra Civil.

La nueva coyuntura trajo consigo un cambio de planes para la política vasca en los Estados Unidos, puesto que ya no se trataba sólo de impedir la victoria de Franco en la guerra, sino también de subrayar a sus interlocutores la naturaleza antidemocrática del Gobierno de la España franquista. Centraron así sus esfuerzos en demostrar el carácter profundamente antidemocrático del régimen, que entendían debía impedir a 
los Estados Unidos reconocerlo otorgándole legitimidad. Así, hasta la entrada de Estados Unidos en la II Guerra mundial en 1941, la acción exterior vasca se concentró en obtener simpatizantes para la causa vasca, tanto en el Departamento de Estado como en la sociedad liberal neoyorquina, y obtener canales de financiación para los refugiados.

El estallido de la II Guerra mundial y la derrota francesa en junio de 1940 colocó a los miembros del Gobierno vasco en una situación muy compleja. El Gobierno de Francia tomó la decisión de mantener las distancias con el exilio republicano español, para no enemistarse con Franco y evitar el surgimiento de un nuevo frente militar en los Pirineos, que se habría producido si España hubiera entrado en guerra a favor de Alemania. Aunque Aguirre dio orden de apoyar a los Aliados sin condiciones, la actitud del Gobierno francés llevó al Gobierno vasco a la búsqueda de otros interlocutores que aceptaran su colaboración para acabar con el totalitarismo nazi y fascista, y también con el franquismo. Así, mientras el lehendakari Aguirre sobrevivía a su odisea en la Europa ocupada, Irujo buscó en Londres llegar a acuerdos con Gran Bretaña y con la Francia del general De Gaulle, mientras los delegados vascos en los Estados Unidos estrecharon lazos con el Gobierno de este país, todavía neutral en la guerra.

La reaparición de Aguirre en Nueva York en 1941 propició el establecimiento del centro neurálgico de la política vasca en los Estados Unidos. En un principio, la política del Departamento de Estado buscó desmarcarse de cualquier tipo de relación oficial con una institución menor. Sin embargo, después de que Estados Unidos entrara en la guerra en diciembre de 1941 las ofertas de colaboración brindadas por el Gobierno vasco al Gabinete Roosevelt comenzaron a ser tenidas en cuenta. Así, el lehendakari encontró interlocutores dentro del Departamento de Estado y de la Casa Blanca dispuestos a escuchar su interpretación sobre la naturaleza ideológica de la II Guerra mundial.

De este modo, la acción exterior vasca se centró en ofrecer a diferentes agencias estadounidenses del Departamento de Estado (COI, OSS, CIAA), del de Justicia (FBI) y del de Defensa (el Servicio de Inteligencia Militar), servicios de carácter propagandístico, informativo y de espionaje -a través del Servicio Vasco de Informaciónpara hacer frente a las fuerzas del Eje en Europa y Latinoamérica, brindando a todos ellos la plena colaboración del Gobierno vasco. Precisamente, en el subcontinente americano los ofrecimientos vascos cobraron especial relevancia, gracias a un acuerdo entre el Gobierno vasco y los servicios de inteligencia estadounidenses, firmado en mayo de 1942 y cuyo contenido exacto aún no es conocido. Gracias a la confesionalidad católica y al programa político demócratacristiano del PNV, el Gobierno vasco se perfiló como un interesante aliado para asegurar mediante labores de propaganda e información el patio trasero de los Estados Unidos ante la evidente influencia de las corrientes ideológicas de carácter fascista que promovieron el antiamericanismo sobre este territorio. Por tanto, en este contexto, en el que los dirigentes vascos contaron con mayores posibilidades de éxito para conseguir sus objetivos, el Servicio Vasco de Información se convirtió en un instrumento para la materialización de un proyecto político del Gobierno vasco y también del PNV.

Sin embargo, esta colaboración quedó en un segundo plano cuando entraron en escena aspectos de mayor relevancia para el Gobierno estadounidense, como la reconstrucción europea y el auge del comunismo en Europa. Por este motivo, en este estudio se ha puesto de manifiesto que la enorme carga de responsabilidades que adquirió el Gobierno de Washington durante la posguerra europea llevó a que 
este delegara en Gran Bretaña parte de su gestión política en Europa, justo en un momento en el que los británicos buscaban el acercamiento a la dictadura española. El ascenso de la Unión Soviética, que salió ampliamente reforzada de la II Guerra mundial, y el miedo a que el comunismo pudiera expandirse por Europa, puso en alerta a los planificadores políticos estadounidenses, que vieron peligrar la hegemonía de los Estados Unidos en la escena internacional. Estas cuestiones, demostradas ya por otros autores, han sido utilizadas de base contextual en este trabajo para mostrar que no sólo el Gobierno de Washington no recompensó las labores prestadas por el exilio vasco durante la II Guerra Mundial con una acción decidida contra Franco -mayormente porque los estadounidenses no se comprometieron políticamente a nada-, sino que este optó por una solución estratégica: el progresivo acercamiento a la España franquista como forma de poner freno a la expansión del comunismo por el Mediterráneo.

A partir de aquel momento, los dirigentes vascos reconfiguraron su estrategia, fijando nuevos elementos. Adecuaron la acción exterior del Gobierno vasco a los intereses políticos y económicos de los Estados Unidos para evitar puntos de desencuentro y con la finalidad de mostrarles que su Ejecutivo sería un útil aliado para el momento en el que decidieran apostar por la democracia en España. De este modo, las relaciones entre el Gobierno vasco y los Estados Unidos entraron en una nueva fase marcada por el contexto de la Guerra Fría (1947-1991).

En este nuevo marco, el Gobierno vasco dio un salto cualitativo en su estrategia, pasando de desplegar una política netamente soberanista y diferenciadora, actuando al margen del Gobierno republicano español, como había ocurrido desde abril de 1939 , a trabajar como sus interlocutores políticos ante las autoridades estadounidenses.
Su objetivo: convencer a las autoridades estadounidenses de que sí existía una alternativa al franquismo y que esta, en caso de hacerse con el poder en España, no significaba en absoluto el progreso en ella del comunismo. En este sentido, los planificadores políticos de la acción exterior del Gobierno vasco conjugaron la estrategia atlantista con la doctrina política demócratacristiana, utilizando esta última como una de sus principales bases discursivas para llevar a cabo campañas propagandistas antifranquistas en Estados Unidos en las que se pusiera en valor la alternativa democrática para España. De este modo, la confusión entre el PNV y el Gobierno presidido por Aguirre se puso de manifiesto en esta estrategia, quedando marcada por la ideología del principal partido del Ejecutivo (situación que se produjo a lo largo de casi todo el exilio). Ciertamente, la mayor parte de los partidos que compusieron el Gobierno vasco no fueron en absoluto demócrata-cristianos, hasta el punto de que entre 1946 y 1948 contaron con un consejero comunista, pero la imagen que presentaron los delegados vascos en los Estados Unidos fue básicamente la del PNV.

En buena manera, el objetivo principal fue participar de cualquier iniciativa que permitiera la recuperación de la democracia en España, porque sólo así podrían restaurar el autogobierno vasco. De este modo, cuando la cuestión española comenzó a ser debatida en el Consejo de Seguridad y la Asamblea General de la ONU en 1945, los dirigentes vascos se implicaron con decisión, al interpretar que la clave de la batalla antifranquista se encontraba en las arenas políticas de la ONU. Esta institución internacional y la conexión con los Estados Unidos, el principal inspirador de este organismo, se presentaron así como la mejor opción para combatir al franquismo, aislándolo diplomática y económicamente.

Los dirigentes vascos apostaron, entonces, por obtener el apoyo de los Estados Unidos 
en este organismo, convencidos de que así conseguirían acabar con el régimen franquista. En consecuencia, entre 1945 y 1953 avalaron la utilidad práctica del Gobierno de la República y del plan monárquico-socialista de Indalecio Prieto como alternativas democráticas viables para la contención del comunismo. Un giro estratégico del Gobierno vasco que, impulsado y protagonizado por José Antonio Aguirre, Antón Irala y Jesús Galíndez, se llevó a cabo con una visión demasiado optimista tanto del contexto internacional como de la posibilidad real de que los Estados Unidos tomara medidas efectivas contra Franco.

El origen de esta propensión a ver y juzgar la política exterior estadounidense de la forma más favorable a sus intereses se ha encontrado en la estrategia atlantista diseñada por Aguirre que, desde el momento de su planificación, estuvo plagada de ensoñaciones utópicas que sobrevaloraron la capacidad organizativa y efectiva del Gobierno vasco y que colocaron a los estadounidenses en una hipotética disposición a trabajar a favor de la restauración democrática en España. Partiendo de esta concepción, el lehendakari y los planificadores de la acción exterior vasca, entendieron que detrás de la política española del Gobierno de Washington había algún tipo de compromiso ideológico y moral con el exilio democrático español, y que en el fondo había una jugada maestra para acabar con el franquismo. Evidentemente, malinterpretaron las claves de la política estadounidense. No contaron con que el Departamento de Estado dejara en un segundo plano las valoraciones de los dirigentes vascos y que considerara la alternativa democrática al franquismo una opción carente de suficiente realismo y peligrosa por su probable deriva comunista.

La firma de los pactos de Madrid de 1953, el convenio hispano-norteamericano de ayuda económica y militar a España, fue el auténtico punto de inflexión en las relaciones entre vascos y estadounidenses, ya que se constató el definitivo acercamiento de los Estados Unidos al Gobierno franquista. A partir de aquel momento, los dirigentes vascos fueron más conscientes de las dificultades de obtener resultados positivos de los contactos con un Gobierno que mantenía relaciones amistosas con su principal enemigo. Ahora bien, los dirigentes vascos persistieron en sus relaciones con Washington. Desde ese momento, el objetivo de los representantes vascos en los Estados Unidos se centró en tratar de evitar la renovación de los acuerdos de 1953, denunciar la situación socio-política en el interior de España y la represión sobre la cultura vasca.

Con todo, la constante en la política exterior estadounidense diseñada para España fue dar prioridad a los intereses geoestratégicos y militares, manteniendo el statu quo, política motivada por la desconfianza que durante todo el exilio les generó cualquier alternativa de la oposición democrática. Sin duda, esta estrategia del Gobierno de Washington mermó las expectativas de los dirigentes vascos, pues tuvieron que enfrentarse con una realidad muy distinta de la que cabía esperar de un país al que consideraban el adalid de la democracia internacional. De hecho, este desengaño les llevó a atravesar distintos estados de ánimo que, de algún modo, quedaron plasmados en la evolución que experimentó la estrategia atlantista; un cambio que, por otro lado, se produjo conforme a las posibilidades reales de acción en el marco estadounidense, europeo y español.

Así de la complicada etapa de la Guerra Civil, en la que los delegados vascos hicieron un sondeo para encontrar simpatizantes para la causa antifranquista, siguió la esperanza de los años de la II Guerra mundial, un periodo durante el que creyeron que la entrada de Franco en el conflicto, seguida 
de una intervención aliada, acabaría con el franquismo. De un estado de ánimo optimista se pasó a la progresiva y creciente desilusión que supuso, primero, la pérdida de las expectativas puestas en la ONU, y, segundo, la apuesta de los Estados Unidos por la continuidad del franquismo. Este desencanto, agravado por la desaparición de Galíndez en 1956, el fallecimiento del presidente Aguirre en 1960 y por la distinta política implementada por Leizaola (19601979), su sucesor al frente de la presidencia vasca, se tornó en una adaptación a los nuevos tiempos. La nueva coyuntura requirió que los dirigentes vascos optaran por otro tipo de estrategia en los Estados Unidos, al margen del Departamento de Estado y del Gobierno, y cercanas, entre otros, a congresistas, sindicalistas y periodistas estadounidenses, simpatizantes con la causa antifranquista.

Este cambio de rumbo que se produjo en la política del Gobierno vasco durante la presidencia de Leizaola no impidió que continuaran las labores de lobbying de las delegaciones vascas de Nueva York y Washington. Un síntoma, empero, de que el exilio vasco notenía muchas alternativas a las que agarrarse y de que los planificadores de la política pro-estadounidense del Gobierno vasco mantenían el convencimiento de que, con una presión constante sobre los medios políticos estadounidenses amigos, podrían incomodar al régimen franquista y a su política exterior. En definitiva, a pesar de que en 1953 se constató el acercamiento de los Estados Unidos al franquismo, los impulsores de la acción exterior vasca en Estados Unidos siguieron confiando en el lobbying sobre el entorno político estadounidense como forma de derribar al Caudillo.

Fue en este contexto en el que la figura de Pedro Beitia cobró especial relevancia. Sus labores representativas en Estados Unidos, hasta ahora prácticamente desconocidas, sirven para poner en valor la figura de un delegado (oficioso) que, a partir de 1956, y especialmente después de 1960, se erigió como el principal director de la política vasca en Estados Unidos, trasladando el eje de la estrategia política atlantista del Gobierno vasco desde la Gran Manzana a Washington. Desde la capital estadounidense, se encargó de trabajar cerca de senadores, congresistas y agentes del Departamento de Estado ofreciéndoles información sobre la situación de España, distinta a la ofrecida por el Gobierno español, y de realizar labores de propaganda antifranquista para conseguir apoyos para la causa vasca. No obstante, aunque el eje de la política vasca en Estados Unidos pivotara sobre las gestiones realizadas por Beitia en Washington, sus funciones y actividades de delegado no oficial del Gobierno vasco tuvieron que ser disimuladas a través de la delegación de Nueva York, a fin de evitar controversias que pudieran dañar su posición de funcionario internacional en la UNESCO, la OMS y el Banco Mundial.

Así pues, entre 1961 y 1976, Beitia fue el principal promotor de la causa vasca en Estados Unidos, manteniendo una estrecha colaboración con el vicelehendakari Joseba Rezola (1963-1971), de quien recibió directrices y con el que compartió la idea de mantener la cohesión dentro de las comunidades vascas en América y de establecer un contacto más asiduo entre estas y el Gobierno vasco en el exilio. La relación con el lehendakari Leizaola no fue de lo más amistosa, al menos inicialmente, porque el presidente vasco desatendió las peticiones de Beitia de realizar más viajes a América -especialmente a los Estados Unidos- y de mostrar un mayor interés, más allá de lo puramente económico, hacia los asuntos de la comunidad vasca allí asentada. Aunque la relación entre ambos mejoró con el tiempo, el cambio estratégico con respecto a América, solicitado por Beitia a Leizaola, no se produjo, siendo así el delegado vasco el que continuara 
encargándose en solitario de mantener los contactos con los estadounidenses durante las décadas de 1960 y 1970. Por este motivo (aunque no exclusivamente), durante aquellos años se produjo un progresivo descenso de los contactos entre los dirigentes vascos y los agentes del Departamento de Estado. Una reducción motivada por las sucesivas prórrogas de diez y cinco años a los convenios de 1953 , que en 1970 acabó provocando la ruptura de relaciones, a raíz de la firma de un nuevo acuerdo bilateral entre el Gobierno de los Estados Unidos y el de la España franquista.

A partir de entonces, los directores de la política vasca dejaron de colaborar con un Gobierno que, para ellos, socavaba las iniciativas a favor de la democracia y que con sus medidas políticas sostenía al régimen franquista. De este modo, Beitia reconvirtió la estrategia política atlantista, centrándose sólo en aquellos simpatizantes de la causa vasca situados en el Congreso y en los medios de comunicación, para presionar al Gobierno de Estados Unidos y que este, a su vez, condicionara los acuerdos que firmara con el Gobierno español al establecimiento de medidas liberalizadoras, que llevaran a España hacia un sistema democrático. Con todo, no fue hasta mediados de la década de 1970, cuando las cosas cambiaron en un sentido positivo, aunque en parte fuera motivado por la muerte de Franco en diciembre de 1975. Al año siguiente, las labores de lobbying de Beitia comenzaron a obtener victorias de especial notoriedad, consiguiendo -entre otras cosas- que sus «amigos del Capitolio» condicionaran la renovación de los acuerdos de ayuda mutua y de defensa (convertidos en Tratado de Amistad y Cooperación) a la implementación de medidas democratizadoras en el aparato institucional del Estado español. Sin embargo, para entonces, la rehabilitación de las instituciones democráticas en el País Vasco era un objetivo completamente real y alcanzable.

\section{Le Movimiento Ibérico de Liberación (MIL) et ses représentations dans la presse : mythes et mystifications ${ }^{1}$}

\section{Canela LLECHA LLOP}

Le Movimiento Ibérico de Liberación (MIL) fait partie de ces groupes politiques qui surgissent dans les années soixantedix et qui, refusant de se limiter à des objectifs antifranquistes, portent un projet révolutionnaire imprégné d'une conception internationaliste de la lutte. Ce travail de recherche cherche à approcher ce petit groupe anticapitaliste essentiellement au travers de ses représentations médiatiques. Pour ce faire, la thèse privilégie une approche double, qui croise perspective diachronique - un parcours de la presse sous le franquisme jusqu'aux médias en démocratie - et regard synchronique - une étude conjointe et comparative de différents journaux. L'examen du discours de presse relatif au MIL présente en effet un intérêt méthodologique majeur, dans la mesure où il fait apparaître une constellation d'ethos qui tient lieu d'identité politique au MIL. Les procédures de nomination ou de qualification du groupe, si elles en disent long sur les différentes configurations discursives dont elles émanent, contribuent à donner du MIL un portrait au kaléidoscope, qui cristallise toujours les langages et les problématiques contemporaines. En confrontant les textes du groupe lui-même à ceux des médias, la thèse aborde ce qui advient dans les jeux d'écart, de distorsion ou de recouvrement que cette mise en regard fait apparaître. Il s'agit d'étudier ce qui se joue au cœur de ces dispositifs rhétoriques, pour comprendre

1 Thèse d'Études Hispaniques en cotutelle soutenue le 12 décembre 2014 à l'Université Paris Ouest Nanterre La Défense, devant un jury composé de Mmes et MM. les Professeurs Bénédicte Brémard, Marie-Claude Chaput (directrice) Francis Demier, Géraldine Galeote, Pilar Martinez Vasseur, Julio Pérez Serrano (directeur). 